\title{
Comparison Effect of Different Aspects of Weight on Some Factors related to Physical Fitness among Female and Male College Students in Bushehr
}

\begin{abstract}
Background and objective: It is little known about physical fitness and the effects of body mass index (BMI) among college students. Therefore, the purpose of this study was to study the effects of various aspects of weight on physical fitness and comparison of these factors among female and male college student of Bushehr city.

Materials and methods: In this quasi-experimental study 149 students were selected from Payame Noor University, Bushehr branch. Based on body mass index (BMI) these students were divided into three groups: obese and overweight, normal weight and underweight group. Different physical fitness was assessed using standard college tests. SPSS 16 was used for analysis of data at levels of $\alpha<0.05$. $T$ independent test were used to analyze the data of two of the groups.

Results: Mean of physical fitness tests was higher in underweight students. There were a significant differences in all tests, 540 meter $(p<0.001), 4 \times 9$ meter run $(p<0.001)$, sit-up test $(p<0.001)$ and push up test $(p<0.001)$ and vertical jump ( $p<0.001$ ) among male and female students.

Conclusion: Overweight/obese students had poorer performance in cardiovascular endurance, agility and power of lower limb than non-obese subjects. Results of this study show that female students had lower scores on all fitness components.

Paper Type: Research Article.

Keywords: Physical fitness, Cardiovascular fitness, Body mass Index (BMI), Colle students, Bushehr.

Citation: Shakiba S, Shojaeizadeh D, Sadeghi R, Azam K. The effectiveness of educational intervention based on the health belief model on eating style and the severe reduction of menstrual pain among clinical personnel of the Imam Khomeini Hospital Complex. Iran J Health Educ Health Promot. Autumn 2016;4(3): 226-235.
\end{abstract}

Ali-Asghar Fallahi

Assistant Professor, Department of sport sciences, Faculty of Education \& Psychology, Shiraz University, Shiraz, Iran

Mohammad-Hassan Abdollahi

* Assistant Professor, Department of sport sciences, Faculty of Education \& Psychology, Shiraz University, Shiraz, Iran (Corresponding author) abdollahi.1975@yahoo.com

Received: 9 December 2015 Accepted: 25 November 2016 


\section{بررسى و مقايسه اثر جنبههاى مختلف وزن بر برخى از عوامل آمادكى جسمانى} در دانشجويان دختر و يُسر شهرستان بوشهر

على اصغر فلاحى المادي

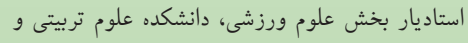
روانشناسى، دانشكاء شيراز، شيراز، ايران

محمد حسن عبدالهي

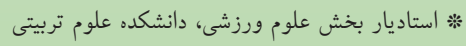

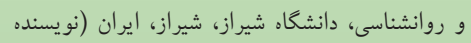
مسئول) abdollahi.1975@yahoo.com

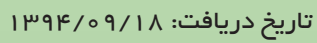

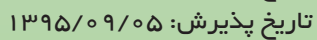

\section{O}

زمينه و هدف : در مورد عوامل آمادگى جسمانى و تأثير تغييرات شاخص تودة بدنى بر آن آن در دانشجويان

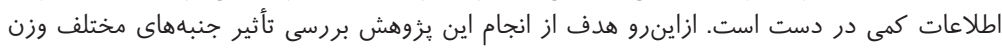

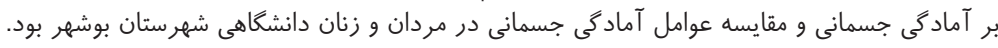

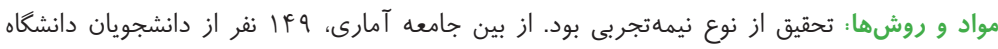

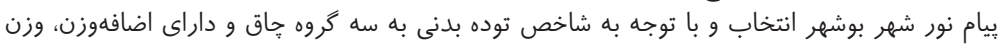

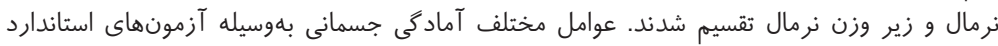

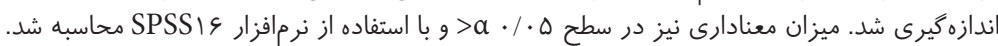

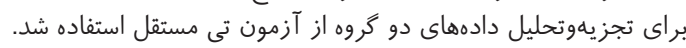

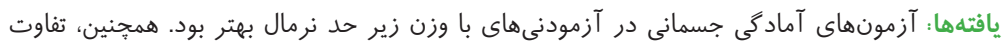

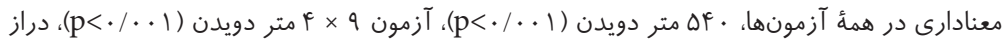

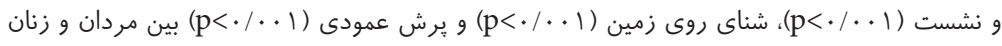

دانشجو وجود داشت.

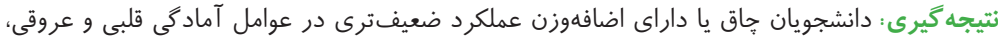

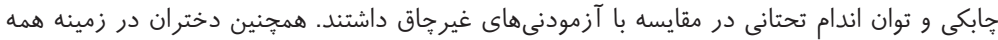

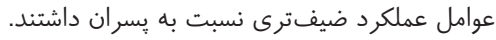

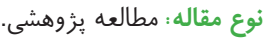
كليدوازه : آمادگى جسمانى، آمادگى قلى مطنى و عروقى، شاخص توده بدنى، دانشجو، بوشهر.

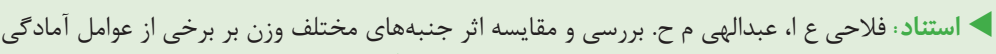

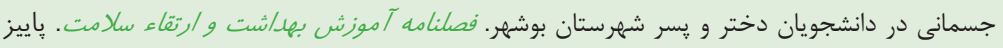




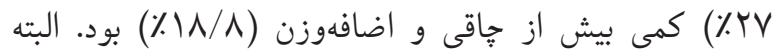

ميزان اضافهوزن و جاقى در پِران بيشتر از دختران بود. در اين

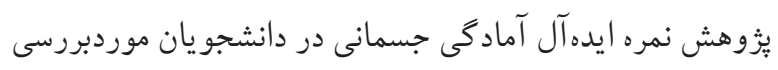

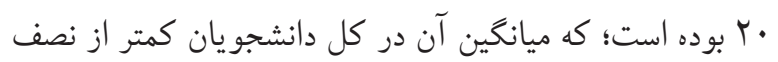

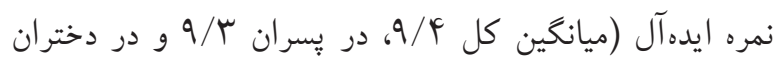

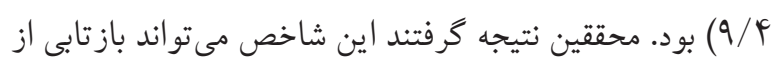

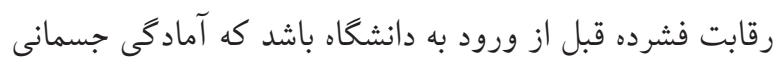

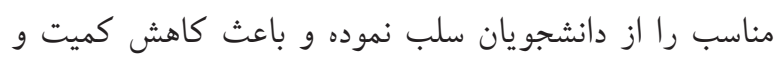

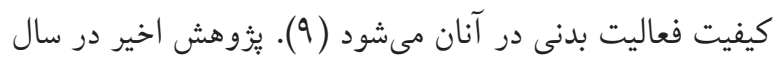

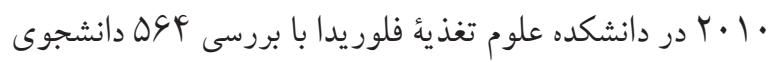

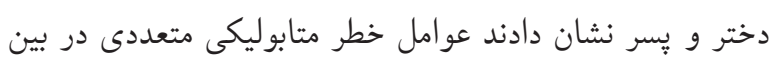

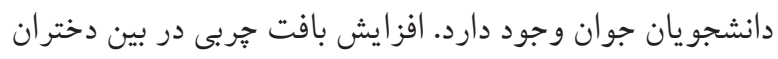

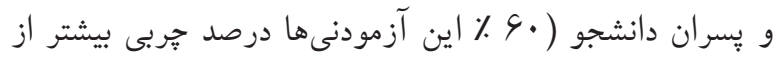

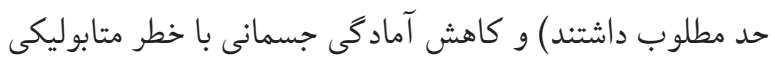

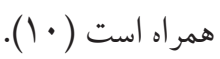
برخى از يُوهشها نشاندهنده تفاوتهاى جنسيتى در

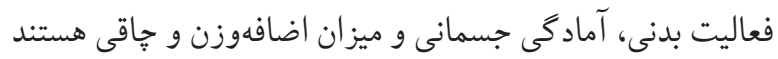

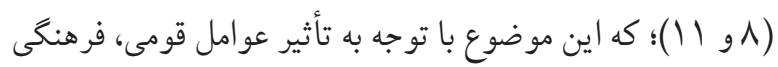
و بومشناختى در فيزيك بدنى و جاقى تفاوتهاى بيشترى را

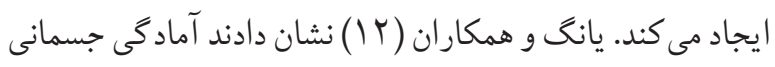

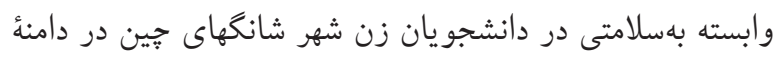

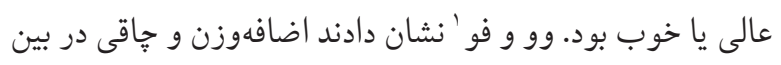

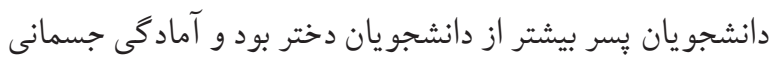

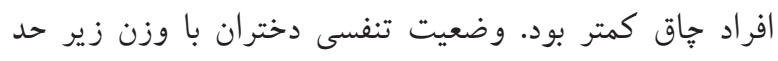

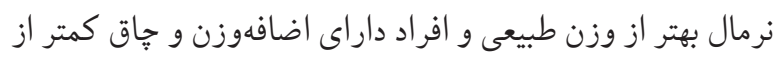

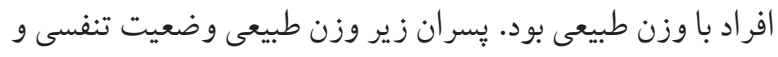

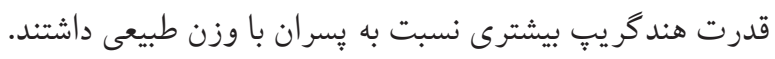

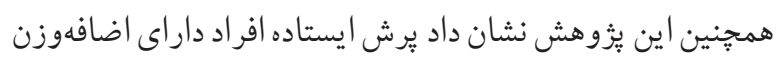

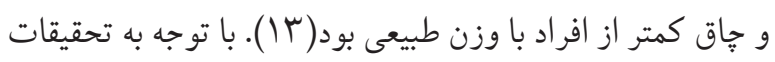

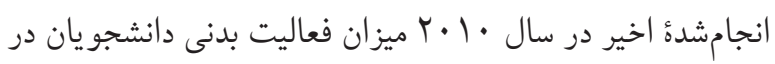

باوجود شواهد روشن در رابطه با فوايد سبك زندگى فعال، كمبود

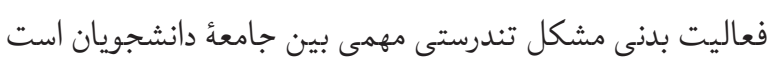

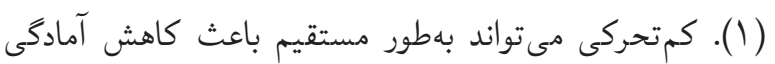

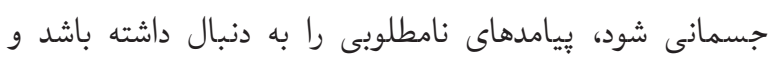

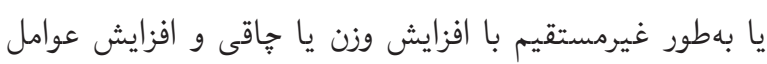

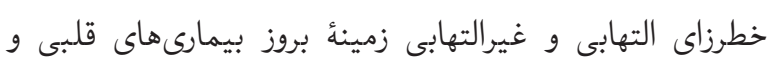

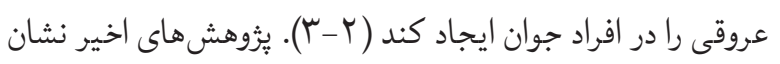

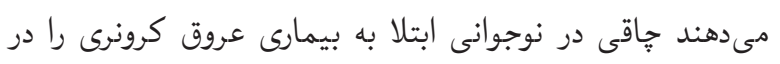

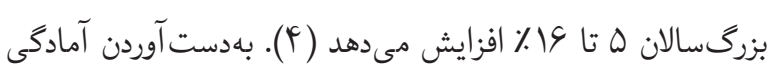
جسمانى مطلوب فوايد زيادى براى سلامت دانشجويان و همه فئ

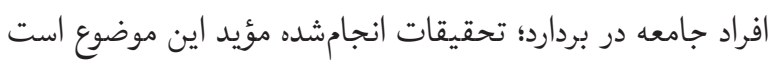

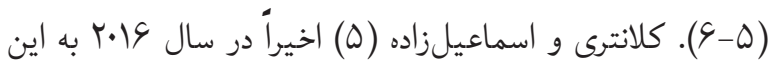
نتيجه رسيدند كه آمادگى قلبى و عروقى با دستاوردهاى تحصيلى يسران نوجوان ارتباط معنادار مثبتى دارد. نتايج تحقيق ديكرى بـى دئي نشان داد فعاليت بدنى و ورزشى براى ترى سيخار در دانشجويان

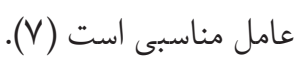
تحقيقات اخير انجامشده در ايران و سراسر دنيا دربارة سلامتى و بررسى آمادكى جسمانى جامعهُ دانشجويان نتايج

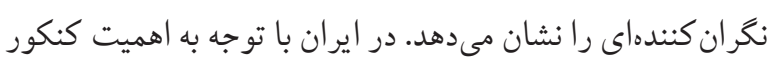

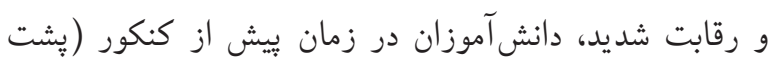

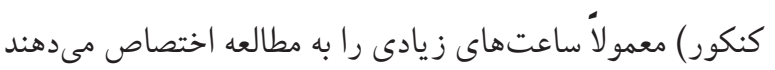

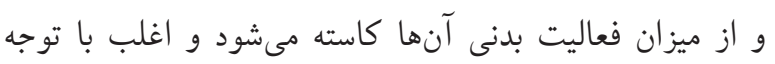

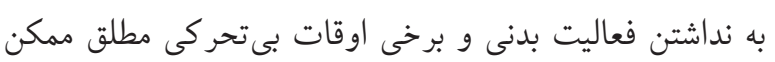

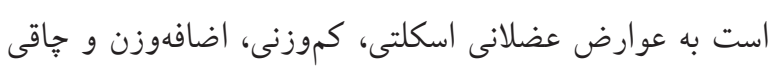

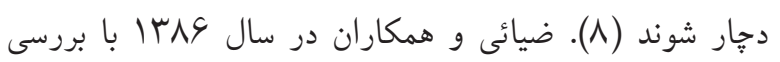

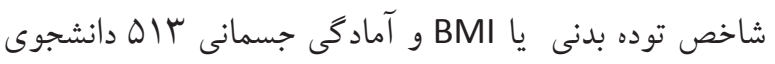

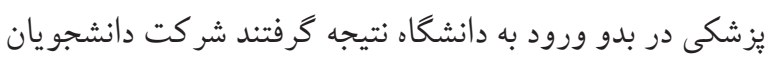

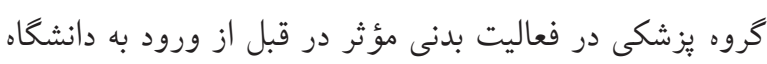
كم مىباشد. نيمى از دانشجويان شركت كننده در اين تحقيق از

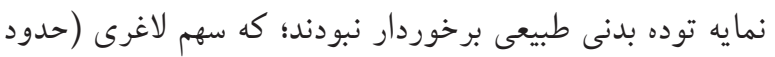


از پِران) براى ارزيابىهاى اوليه كزينش شدند. افراد كمتر از

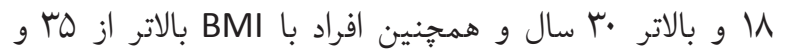
همجنين افرادى داراى منع حركتى يا بيمارى خاص در تحقيق

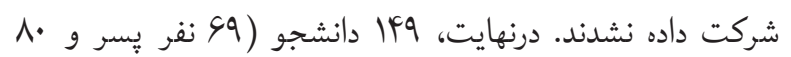

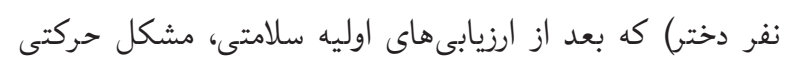

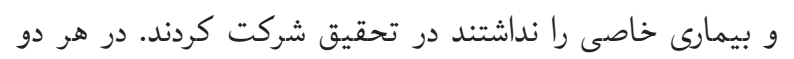

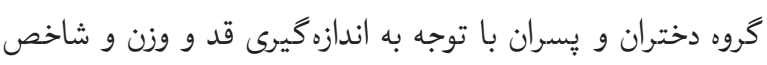

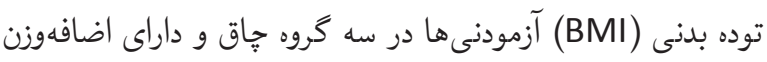

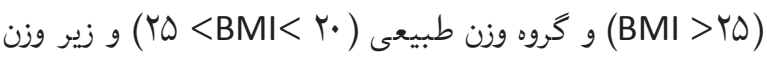

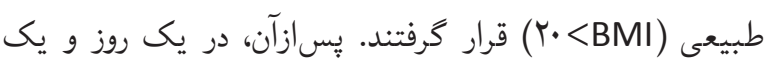

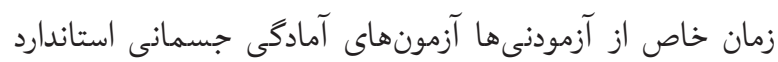

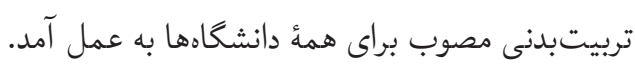

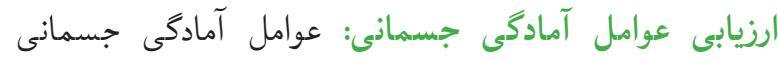

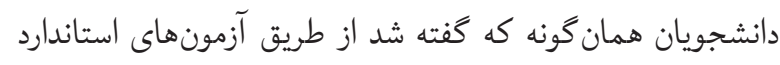
سراسر كشور به شرح زير اندازهكيرى شد.

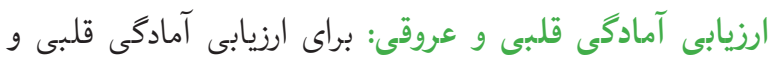

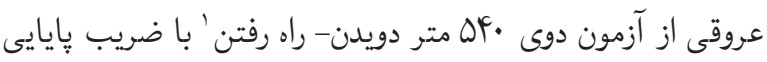

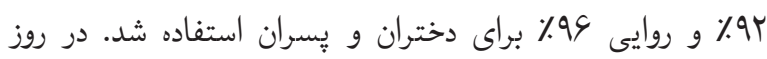

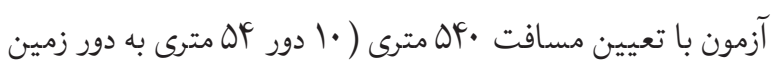

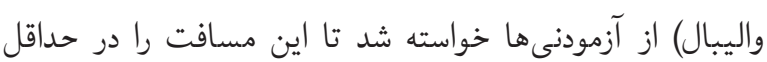

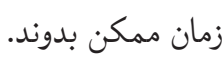

ارزيابى استقامت عضلات شكمى: بهمنظور ارزيابى استقامت

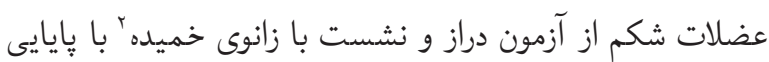
94 ٪ و و وايى قابلقبول بدينصورت استفاده شد كه بعد از تهيه جند تشك مناسب از آزمودنى هاى خواسته شد در زمان يك دقيقه حداكثر تعداد دراز و نشستى را كه مى توانستند انجام دهند.

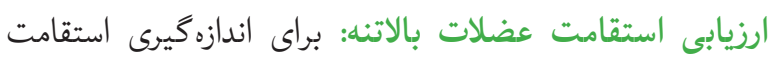

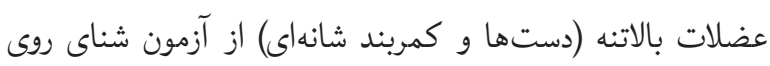

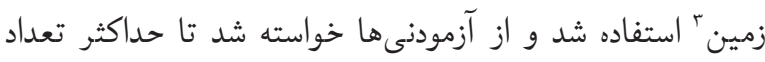

1. 540 meter/Six Hundred yard Run-Walk Test

2. Sit-Up (Bent Knees) Test

3. Press Up Test
هر دو جنس كم است و يافتههاى اين يُووهشها دلالت بر اين

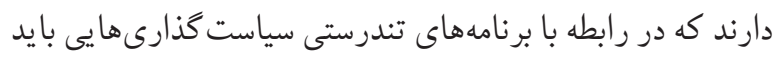

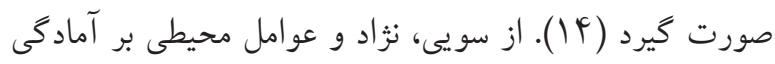

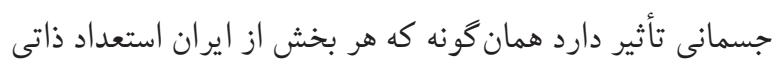

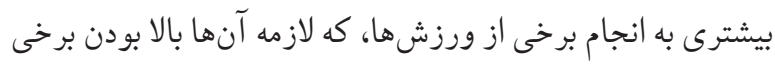

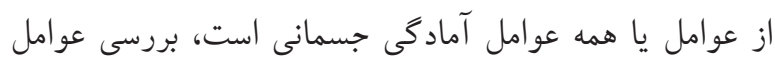

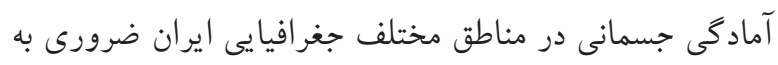
نظر مىرسد؛ ولى تحقيقات جندانى در اين زمينه صورت نكخرفته

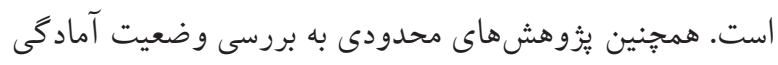
جسمانى دانشجويان يرداختهاند و در ايران يُوهشى كه بـ با توجه به تقسيمبندى شاخص تودة بدنى به بررسى تفاوتهاى جنسيتى

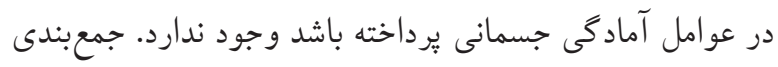

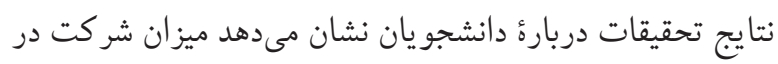

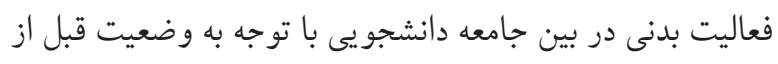

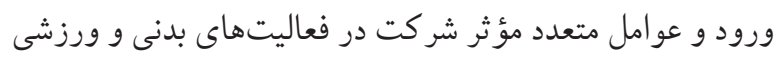
بعد از ورود به دانشكاه، كم است؛ ولى بيامدهاى كم تحركى يان وضعيت آمادكى جسمانى در بين اين دانشجويان كمتر بررسى بدانده

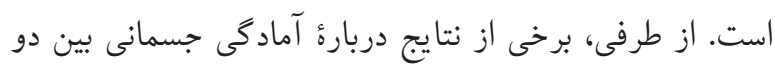

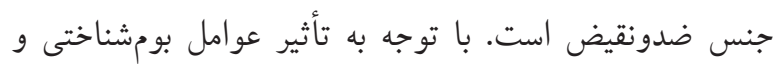

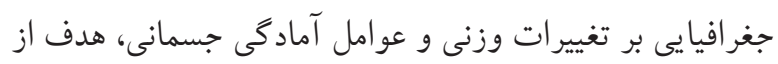

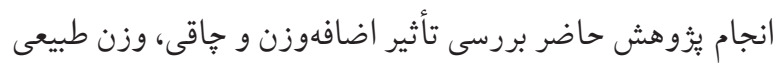
و كموزنى بر عوامل آمادكى جسمانى وابسته به سلامتى و مقايسة اين عوامل بين دانشجويان دختر و پِسر شهرستان بوشهر است.

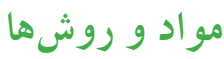
تحقيق حاضر از نوع نيمهتجربى بود. جامعه آمارى آن را دانشجويان پٍر و دختر شهرستان بوشهر تشكيل مى مدادند.

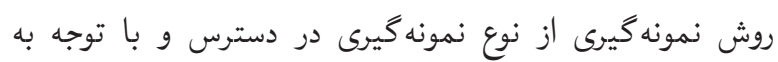

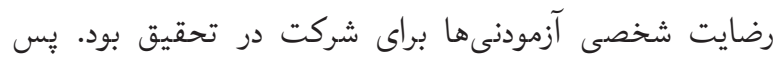

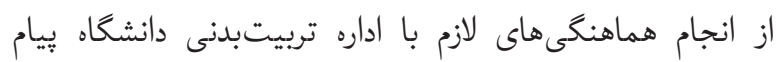

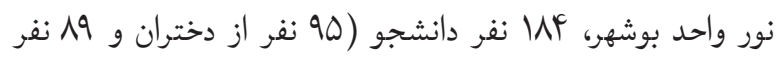


متغيرها با استفاده از آزمون تى مستقل به تفكيك گروهها در جدول ا و بهصورت كلى در جدول ب بهطور خلاصه نشان داده شده است. با توجه به جدول لا، مقايسه بين دختران و ورّران

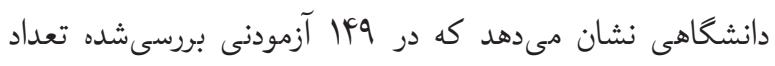
آزمودنىهاى زير حد طبيعى شاخص توده بدنى در دختران بيشتر

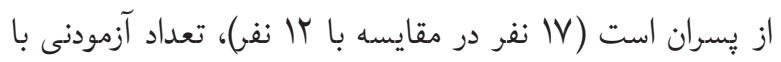
وزن طبيعى نيز در دختران بيشتر از پِّران (YN نفر در مقايسه

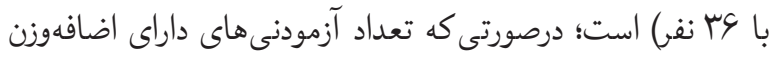

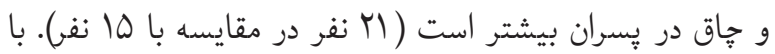

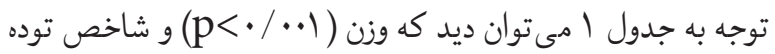

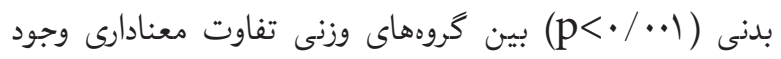

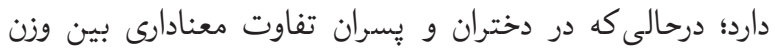

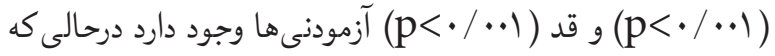

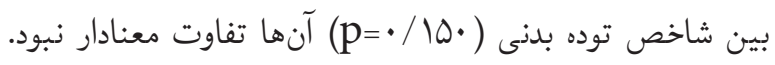

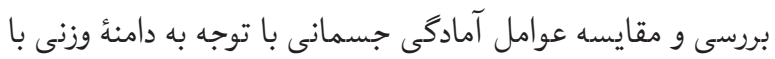

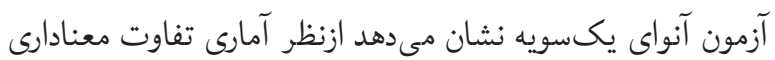

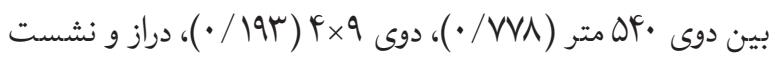

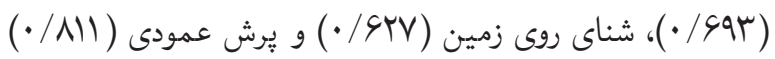
يسران وجود ندارد. با توجه به جدول Y مقايسٔ ميزان مطلق ميانگين عوامل آمادكى جسمانى در يسران نشان مىدهد كه در دامنه بهاى

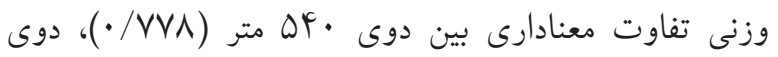

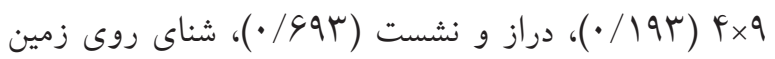

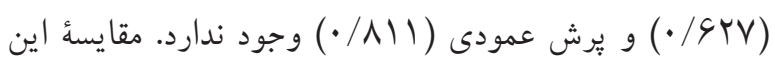

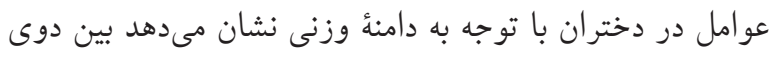
•

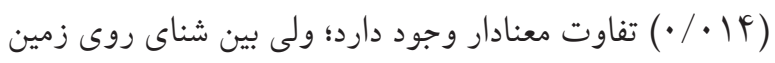

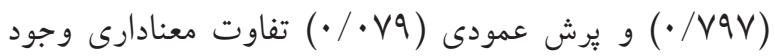

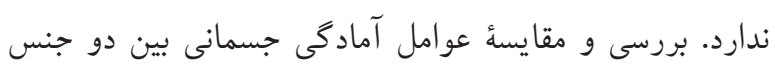

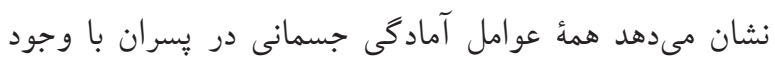

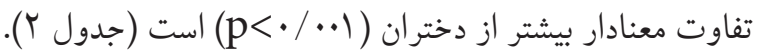

شناى روى زمين را در مدت • ب ثانيه انجام دهند.

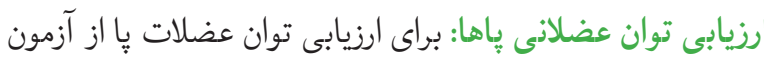

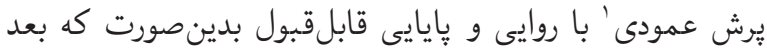

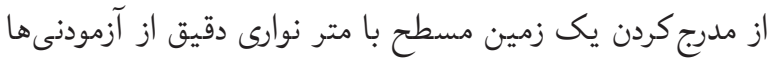
خواسته شد حداكثر مسافت طولى را بيرند.

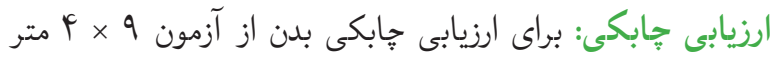

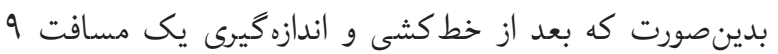

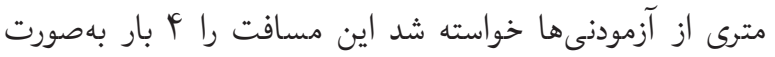
رفت و برگشتى با حداكثر سرعت ممكن طى كنند (19).

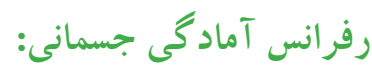
اندازه كيرى شاخصهاى آنترويومتريكى: شاخصهاى آنترويومتريكى اندازه خيرىشده وزن و قد آزمودنىها بودي؛ كه وزن با استفاده از ترازوى زيمنس ساخت كشور آلمان (دقت

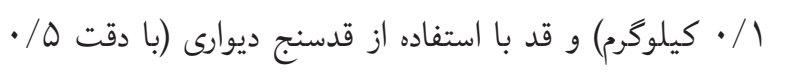
سانتىمتر) اندازه كيرى شد. شاخص توده بدنى آزمودنىها نيز باديا استفاده از فرمول وزن تقسيم بر مجذور قد به متر محاسبه شد.

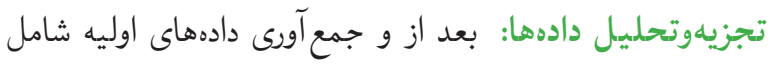
قد، وزن، سن، شاخص توده بدنى و انجام آزمونهاى آمادكى ديى

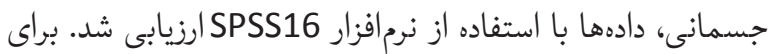
تجزيهوتحليلى دادهها از آزمونهاى توصيفى ميانخين، انحراف داف استاندارد براى بررسى توزيع و طبيعى بودن دادهها، و آزمون

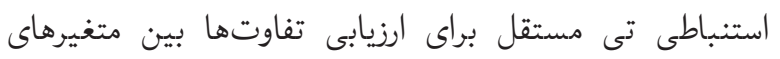

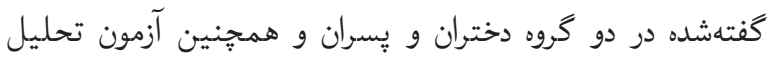

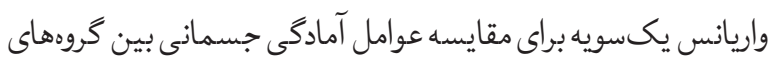
وزنى استفاده شد. ميزان معنادارى نيز در سطح ه• / > $a$ محاسبه شد. يافته ها دادههاى اوليه شركت كنندگان در اين يزوهش شامل سن، قد، وزن و شاخص توده بدنى و همجِنين مقايسه ميزان معنادارى اين ستردي 
ו ו

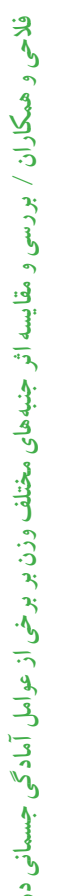

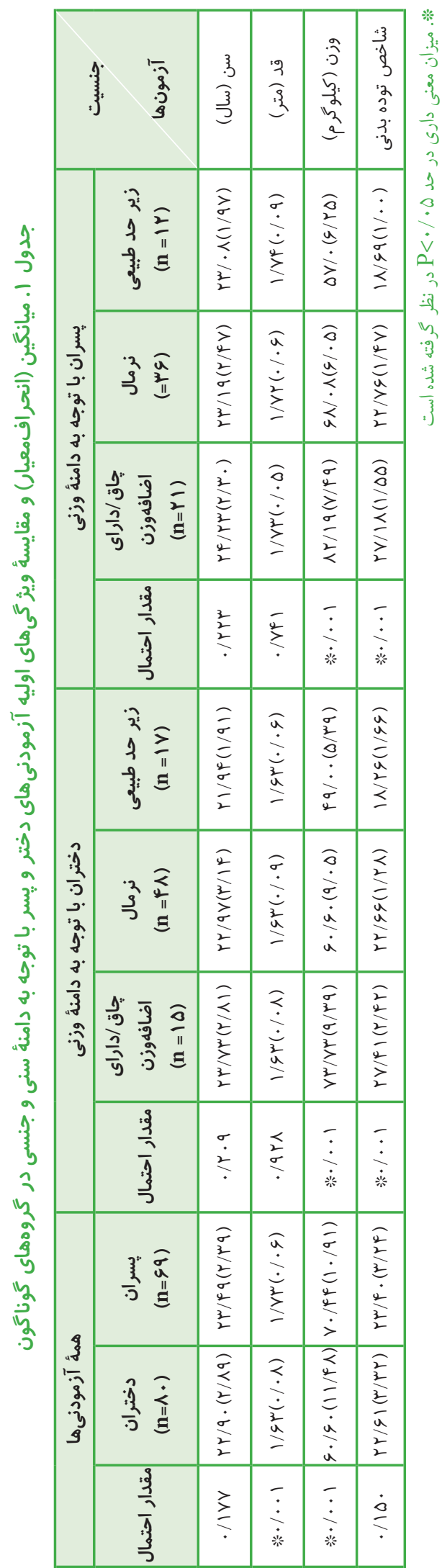

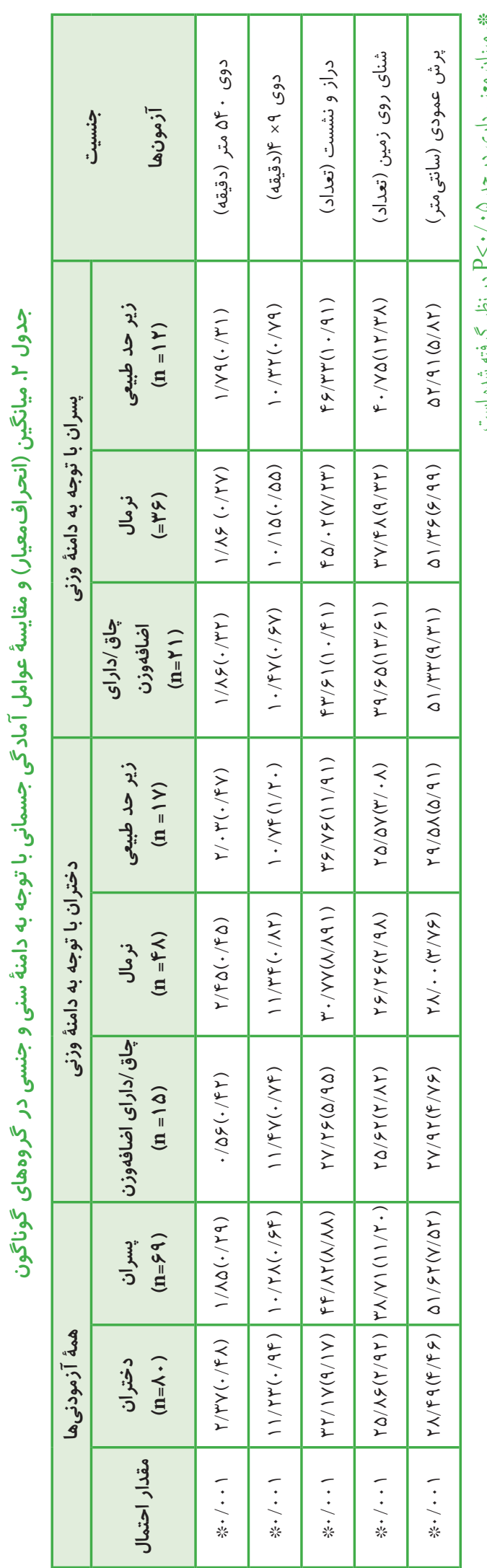


است كه جربى بدن بار اضافى را بر بدن آنها در هنكام كارهايى كه به تحمل وزن نياز دارند اعمال مى كند (IV) ديكر مى تواند اين باشد كه جاقى در مقايسه با غير جاقى به خاطر

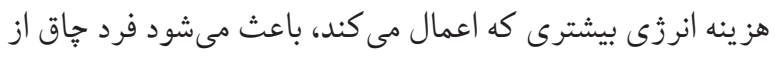

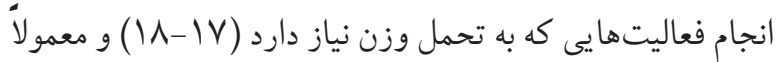

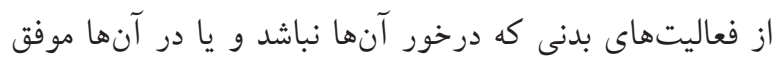
نباشند اجتناب كنند (19). انتقالدادن و بلند كردن بار اضافى ممكن است بر مفاصل بدن افراد جاق بار اضافى ايجاد كند ( • (Y).

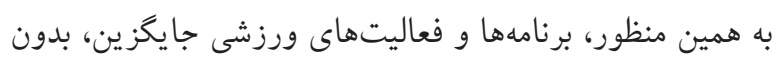
تحمل وزن، نظير دوجرخهوارى، شنا كردن و ديكر ورزشهاى بهاى

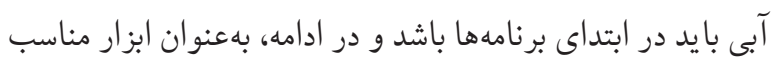

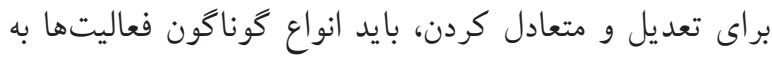

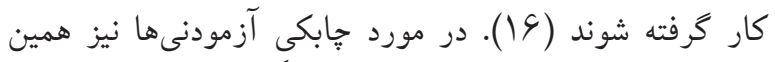

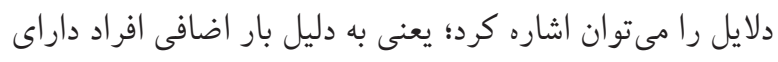
اضافهوزن و جاق در عكسالعمل ها نيز ضعيف تر از افر اد غير جاق باق هستند. بررسى دقيقتر عوامل آمادگى جسمانى در بين گروهها نشان مىدهد كه افراد با وزن زير حد طبيعى در بيشتر آزمونها در مقايسه با ديكر آزمودنىها نتايج بهترى را نشان دادهاند. دليل اين نتيجه احتمالاً سبكتر بودن و كم بودن بار اضافى براى انى انتقال

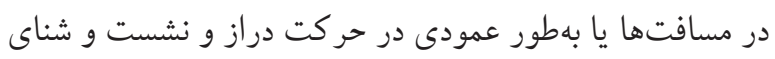
روى زمين است. البته با بررسى ورزشكاران استقامتى كار زبده

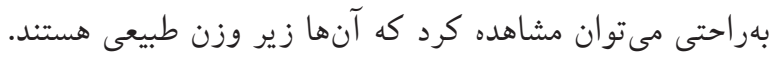
در مورد دختران نيز به همان دلايل كفتهشده مى توان اشاره كرد.

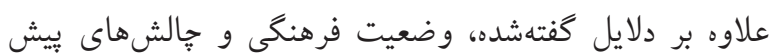
روى شركت در فعاليتهاى بدنى براى دختران نيز از عواملى

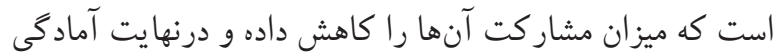
جسمانى آنها را به نسبت پِّران در وضعيت ضعيفترى قرار

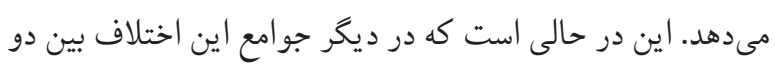

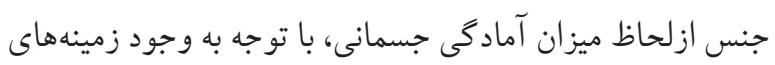
يكسان مشار كت در فعاليتهاى بدنى، كمتر است (· (Y).

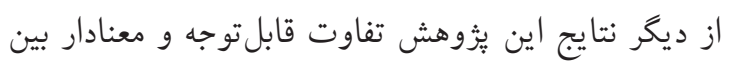
اين يُوهش از معدود يُوهشهايى است كه به بررسى تأثير

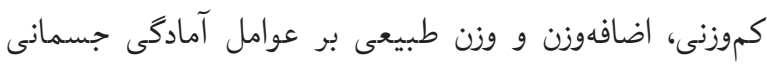
با توجه به تفاوتهاى جنسى يرداخته است. كيتينگ و همكاران

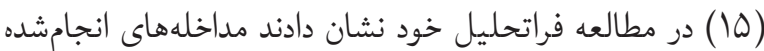
براى افزايش فعاليت بدنى دانشجويان هنوز در مراحل اوليه است

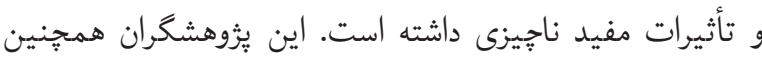

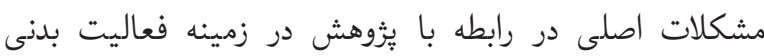

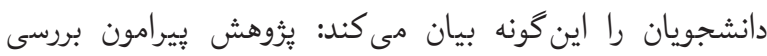
فعاليت بدنى دانشجويان معدود است و اين موضوع مورد غفلت

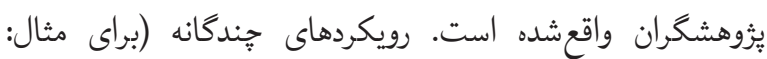
شخصى، روانشناختى و محيطى) براى بررسى رفتارهاى فعاليت

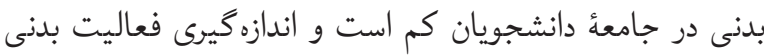
در اين جامعه غيرعينى و متناقض است؛ كه اين موضوع مقايسه

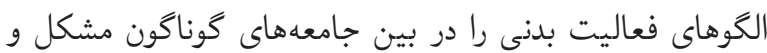
حتى غيرممكن مي سازد (10).

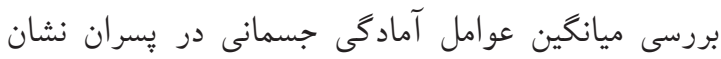

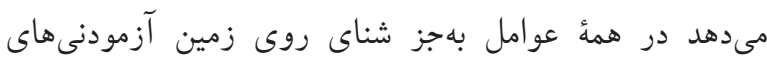

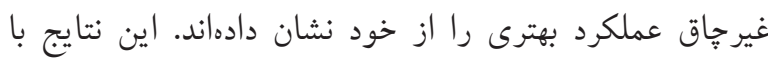
نتيجه يُزوهش دفورج' و همكاران (19) تقريباً يكسان است. البته آزمودنى هاى تحقيق دفورج و همكاران گروه سنى نوجوانان

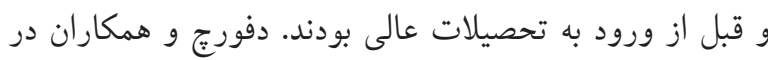

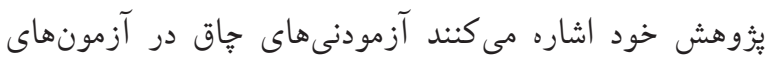

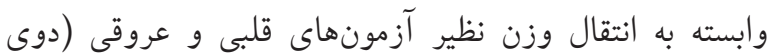

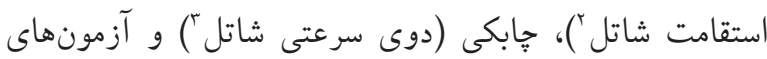
استقامت عضلات شكم (دراز و نشست) توان عضلانى اندام تحتانى (آزمون پرش طولى) نتايج ضعيفتر و در آزمونهاى

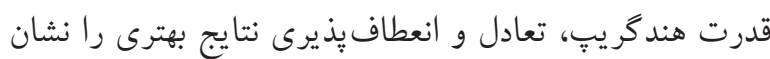

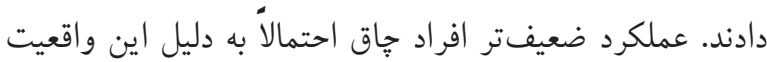

\section{Deforche}

2. Endurance shuttle run

3. Speed shuttle run 
علاوه بر موارد بالا، به دليل تفاوتهاى جنسيتى در پياسخهاى

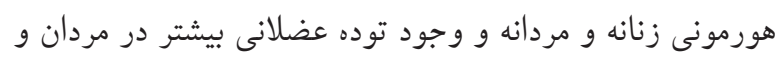

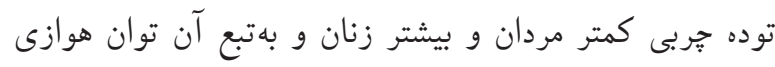

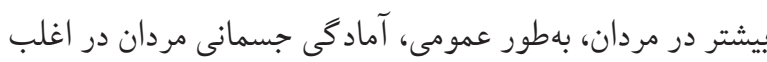

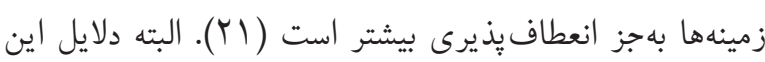

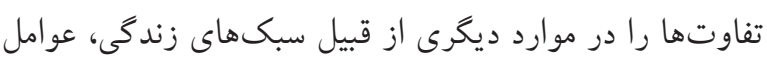

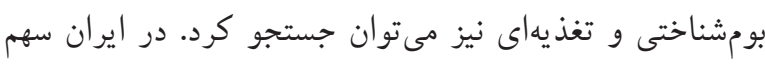

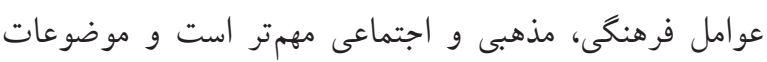

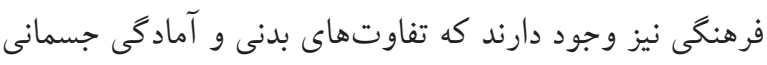

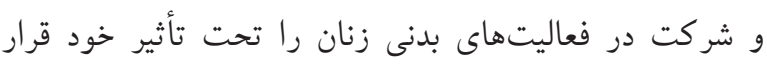

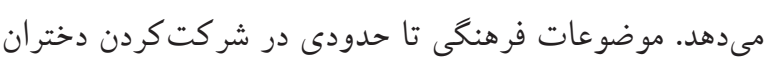

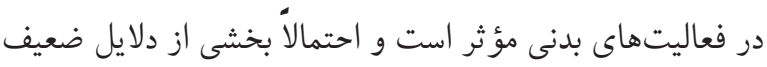

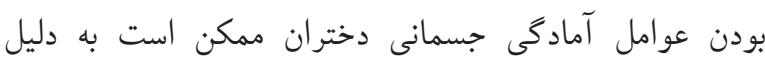

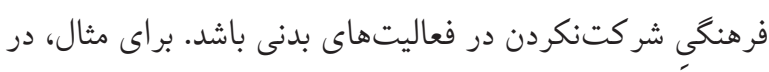

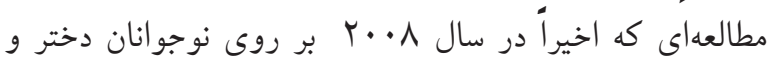

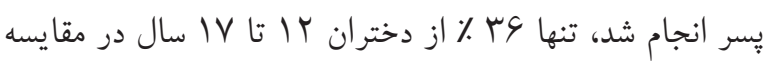

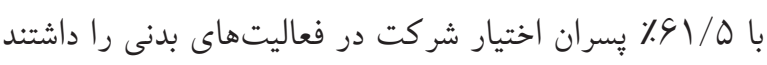

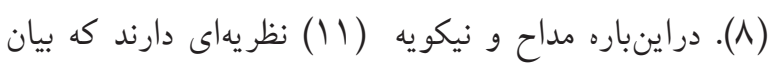

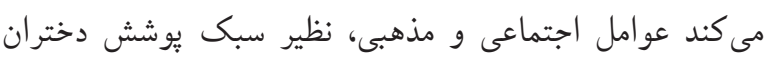

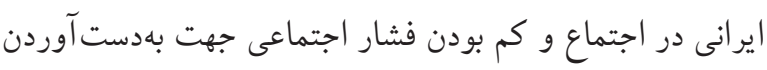

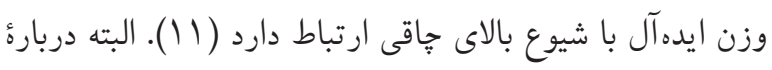

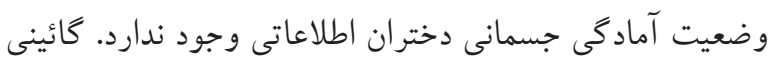

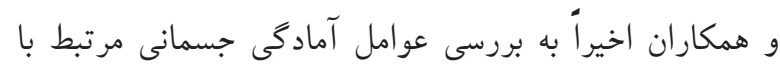

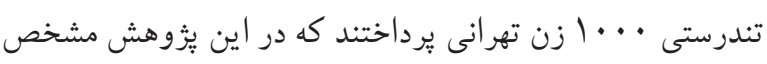

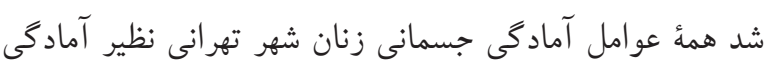

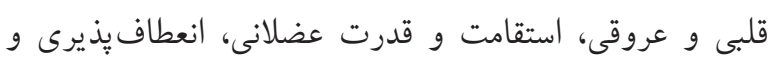

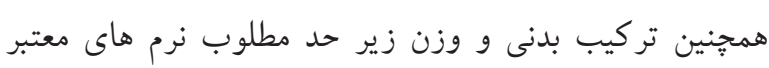

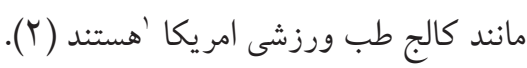

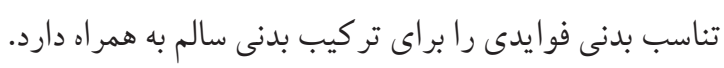

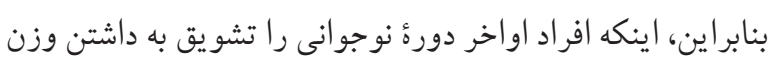

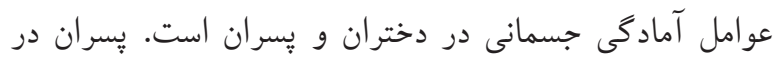

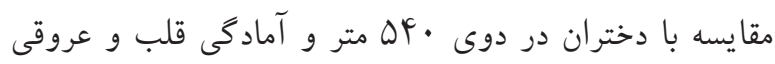

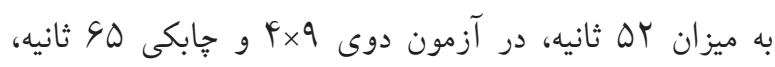

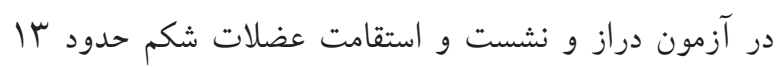
حركت، در آزمون شناى روى زمين و استقامت عضلات اندام آنقام

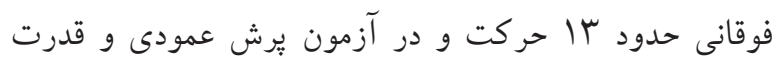

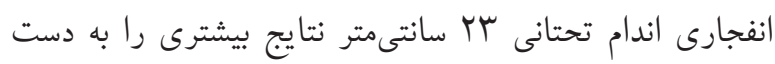

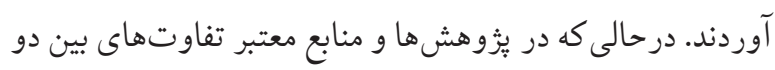

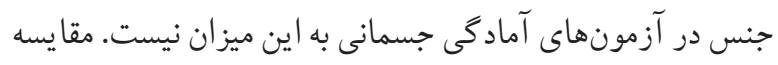

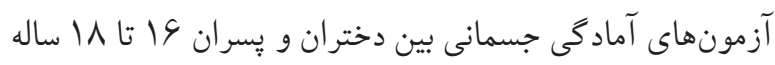

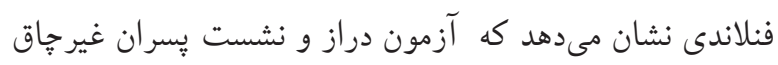

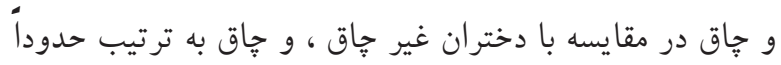

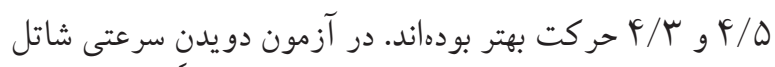

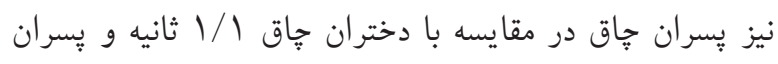

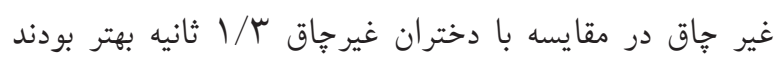

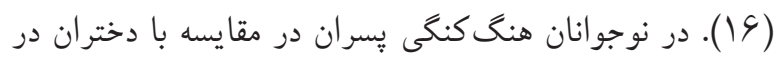

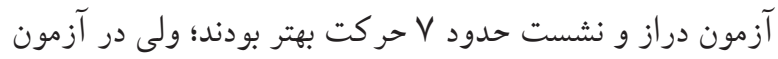

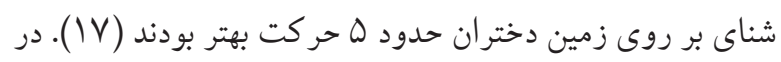

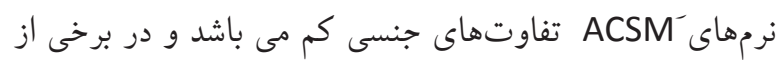

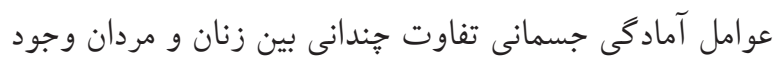

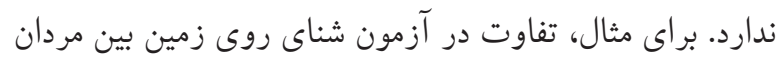

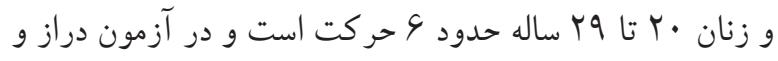

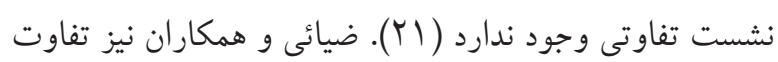

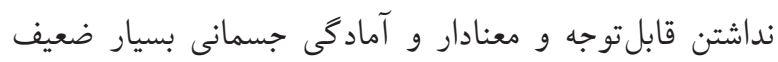

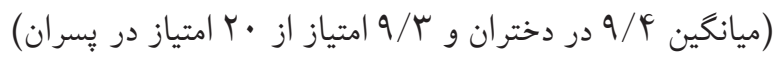

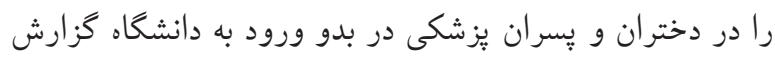

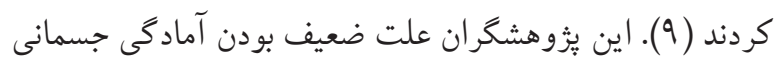

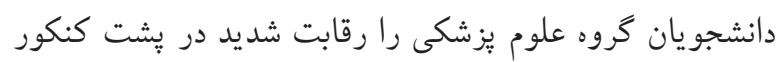

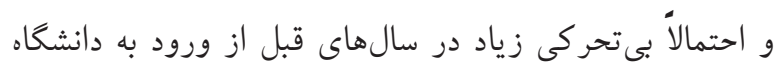

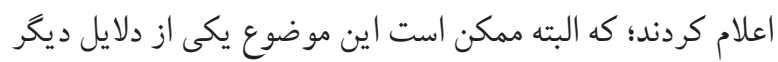
ضعيف بودن نتايج در دانشجو يان بهويثه دختران باشد. 
تحقيقات بعدى در جامعه ايران استفاده كرد.

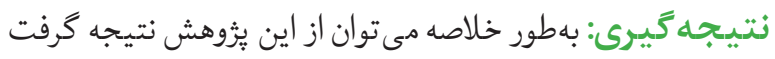
كه زنان و مردان دستهبندىهاى وزنى زير حد طبيعى، طبيعى بهى

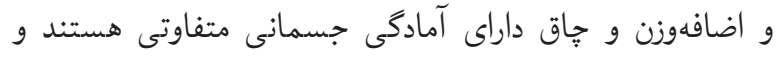

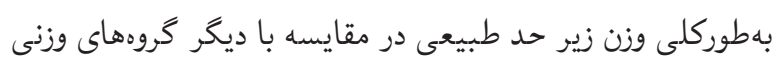

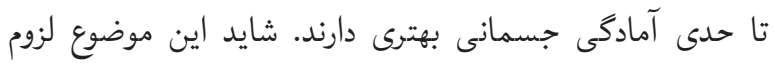
بازنكرى و تعديل شاخص توده بدنى و دستهبندى هاى وزنى با توجه به رويكرد بيشتر اقشار جامعه به سمت داشتن بدنهايى لاغراندام

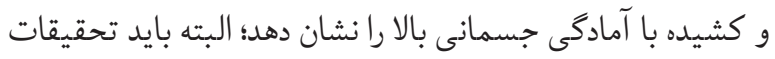

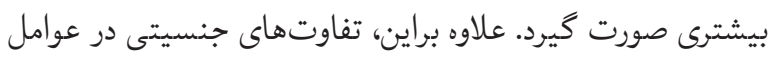
آمادكى جسمانى بين زنان و مردان اين تحقيق نشاندهنده فاصله

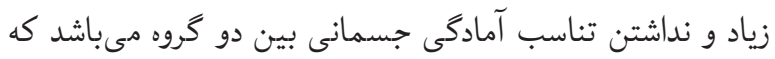

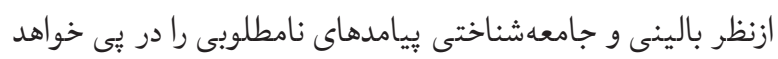

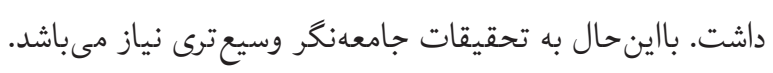

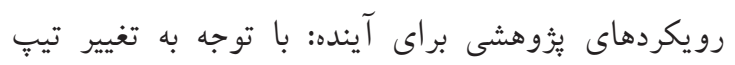

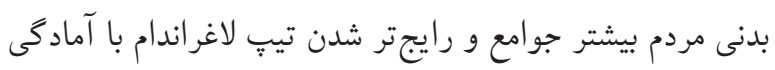

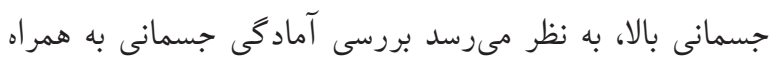

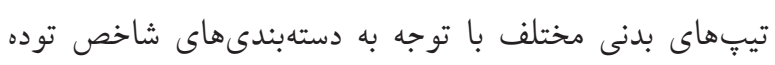

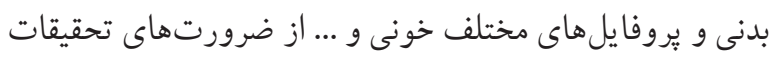

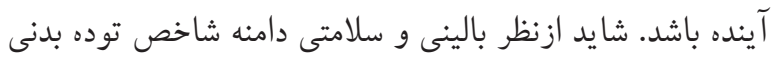

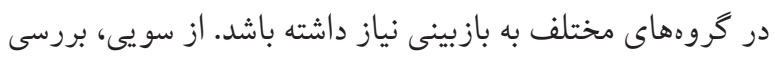

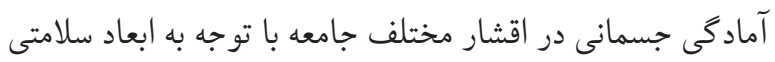
از زوايايى گوناگون مى تواند به ارتقاى سلامتى بيشتر مردم جامعه دئه كمك كند.

\section{Reference:}

1. Tehrani H, Majlessi F, Shojaeizadeh D, Sadeghi R, Kabootarkhani MH. Applying Socioecological Model to Improve Women's Physical Activity: A Randomized Control Trial. Iranian Red Crescent Medical Journal. 2016;18(3).

2. Gaeini AA. Fallahi AA. Kazemi A. Kordi R. Association between Cardiovascular Fitness and Inflammatory Markers in Boys Aged 11-14 Years. Iran J Pediatr; 2009; 19 (3): 262- 270.

3. Tehrani Hadi,Gholian-avval Mahdi, Hasani-kabootarkhani
و آمادگى جسمانى مناسب كرد اهميت دارد. آمادگى جسمانى نقش مهمى در كاهش نشانكرهاى بيوشيميايى خطرناك همراه

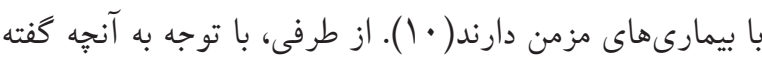

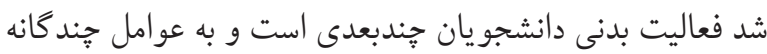
شخصى، روانشناختى، محيطى و امكانات خوابكاهى وابسته است.

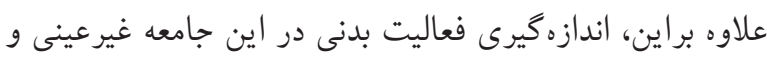
متناقض است؛ كه اين موضوع مقايسه الكوهاى فعاليت بدنى را در بين جامعههاى گوناگون مشكل و حتى غيرممكن مىسازد.

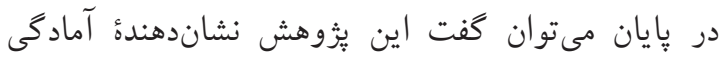

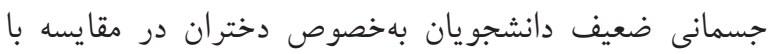
يُزوهشهاى ديكر است و لزوم طراحى سياستهاى همه جانبه

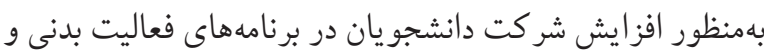

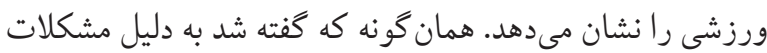

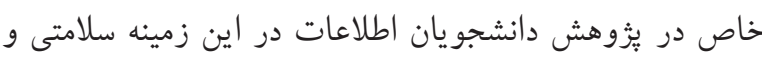

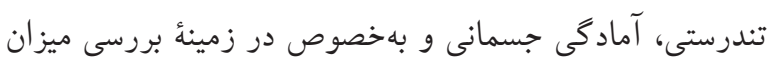
شركت و ميزان فعاليت بدنى روزانه دانشجويان كم است. ازاينرو، تحقيقات بيشترى بايد در اين زمينه بهويثه در ايران

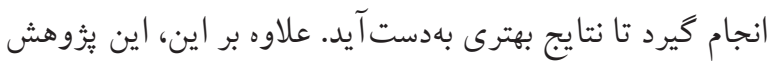

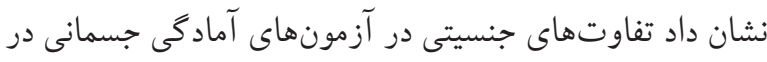

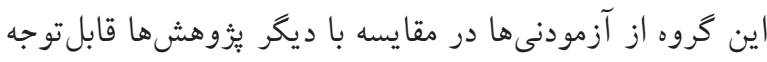

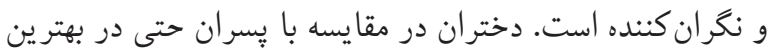

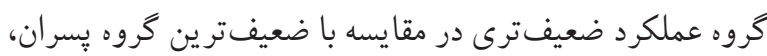

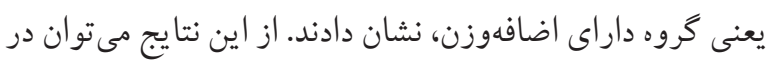

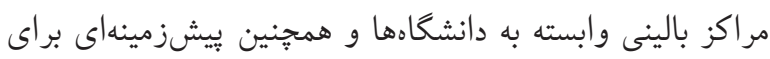

Marzieh, Peyman Nooshin, Vahedian-Shahroodi Mohammad. The impact of new communications technology on promoting women's physical activity. PAYESH. 2016;15(3):293-300

4. Washington Reginald L. Physical Education in Schools Helps Reduce Future Cardiovascular Risk. Circulation 2009; 120: 2168-2169.

5. Kalantari HA . Esmaeilzadeh S. Association between academic achievement and physical status including physical activity, aerobic and muscular fitness tests in 
adolescent boys. Environmental Health and Preventive Medicine. 2016; 21,(1): pp 27-33.

6. Huang G. Jane A. Brezette D. Jim D. Kamla, Stephanie E. Bennett, Patty L. Marcum, Glenna G. Bower and David F. Enzler. Relationship of Physical Fitness and Academic Performance in College Students. for Free Communication: College Students' Attitudes and Decisions Regarding Health-Related Behavior, 2009, 10:15 AM - 12:15 PM, Tampa Convention Center.

7. Shuo-wen Chang. An Inquiry into the Current State of the Various Physical Fitness Performance Levels of Taiwan's College Students and Their Sleeping Habits. (thesis in Master's Thesis). 2009.

8. Taymoori P. Niknami S. Berry T. LubansD. Ghofranipour F. Kazemnejad A. A school-based randomized controlled trial to improve physical activity among Iranian high school girls. International Journal of Behavioral Nutrition and Physical Activity. 2008; 5(18):1479- 5868.

9. Ziaee V, Fallah javad, Rezaee M, Bayat AR. The relationship of Body mass index and physical fitness of 513 medicine student. Journal of Tehran medical school, 2008, 65 (8). 79-84.

10. Sacheck JM. Kuder JF. Economos CD. Physical Firness, Adiposity, and Metabolic Risk Factors in Young College Students. Medicine \& Science in Sports \& Exercise, June 2010. 42 (6): 1039-1044.

11. Maddah M. and Nikooyeh B. Obesity among Iranian Adolescent Girls: Location of Residence and Parental Obesity. J HEALTH POPUL NUTR. 2010;28(1):61-66

12. Yang $\mathrm{XU}$, Yang $\mathrm{YU}$, Ning $\mathrm{AN}, \mathrm{Ru}$ SU. Research on Physical Fitness Conditions of College Female Students in Changchun City [J]. Journal of Changchun Normal University (Natural Science). 2010;2:041.

13. Wu XY, Fu XC. The Research of the Relationship Between the body Mass Index and the Physical Health Variables of the College Students [J]. Journal of Beijing Sport University. 2006;8:028.

14. Waldron J J, Dieser RB. Perspectives of Fitness and Health in College Men and Women Journal of College Student Development. 2010; 51 (1), pp. 65-78

15. Keating X D. Guan J. Piñero J C, Bridges D M. A MetaAnalysis of College Students' Physical Activity Behaviors. Journal of American College Health. 2005; 54(2) 116- 126.

16. Deforche B. Lefevre J. Bourdeaudhuij ID. Hills A P. Duquet W, and Bouckaert J. Physical Fitness and Physical Activity in Obese and Nonobese Flemish Youth. Obes Res 2003;11:434-441.

17. Kwok-Kei Mak. Sai-Yin Ho. Wing-Sze Lo. G Neil Thomas. Alison M McManus. Jeffrey R Day. Tai-Hing Lam. Mak et al. Health-related physical fitness and weight status in Hong Kong adolescents. BMC Public Health. 2010; 10:88.

18. Chia-Yih Wang. Haskell WL. Farrell SW. LaMonte MJ. Blair SN. Curtin L R. Hughes JP. and Vicki L. Burt Cardiorespiratory Fitness Levels Among US Adults 20-49 Years of Age: Findings From the 1999-2004 National Health and Nutrition Examination Survey American Journal of Epidemiology. 2010;171(4): 426- 435.

19. Sothern MS. Exercise as a modality in the treatment of childhood obesity. Pediatr Clin North Am. 2001; 48:4:9951015.

20. Dwyer GB, Davis S E. ACSM's Health Related Physical Fitness Assessment Manual. 3rd ed. Lippincott WilLiams \& Wilkings, Philadelphia. 2008.

21. Marjolein Krul. Johannes C. van der Wouden. François G. Schellevis. Lisette W. A. van Suijlekom-Smit,Bart W. Koes. Musculoskeletal Problems in Overweight and Obese Children. Ann Fam Med. 2009; 7: 352-356. 